\title{
CONSTRUCTION RESEARCH AND APPLICATION OF FUNDAMENTAL GEOGRAPHIC NATIONAL CONDITION MONITORING QUALITY CONTROL SYSTEM
}

\author{
Wenchao Gao ${ }^{1}$, Haitao Zhao ${ }^{1}$, Wenjuan Mao ${ }^{1}, \mathrm{Su}_{\text {Yin }}{ }^{1}$, Zongbiao Tian ${ }^{1}$ \\ ${ }^{1}$ National Quality Inspection and Testing Center for Surveying and Mapping Products, Beijing, China - tian_900014@163.com
}

\author{
Commission III, III/IVb
}

KEY WORDS: Quality control system, Quality control method, Quality control content, Results quality evaluation, Software development

\begin{abstract}
:
The fundamental geographic national condition monitoring uses high-resolution aerial and aerospace remote sensing images to produce digital orthophoto images, land cover classification, geographical and national conditions, databases, statistical analysis and other results to monitor land changes within China's territory, the cycle is once a year. At present, the achievements have been applied in the fields of natural resource management, environmental protection and governance, people's livelihood guarantee, emergency disaster relief, and so on, it is of great significance to provide integrated, standardized and reliable geographic information products to meet the needs of ecological civilization construction. In view of the actual situation of the geographical conditions of the country, such as the organizational mode of production, the technical methods and the requirements of the results, this paper discusses the innovative development of the quality control method, the quality control content, the results quality evaluation and software development, etc., having established a basic quality control system for monitoring the geographical conditions of the country, and applied it in the quality control work of monitoring the geographical conditions of the country carried out in the past four years from 2016 to 2019, effectively guaranteeing the quality of the results, it also provides reference and reference for other important engineering quality control work.
\end{abstract}

\section{INTRODUCTION}

\subsection{Project Description}

According to the State Council's overall deployment of fundamental geographic national condition monitoring work and the transformation and development needs of surveying and mapping geographic information undertakings, the acquisition of geographic national conditions information entered the regular monitoring stage in 2016. In recent years, China organizes task-bearing units in 31 provinces across the country to use the acquired high-resolution aerospace remote sensing images to carry out the annual fundamental geographic national condition monitoring work, completed the coverage of digital orthophotos, surface coverage classification, Geographical factors, Remote sensing interpretation sample, field investigation and verification, production metadata, databases and statistical analysis and so on results of production. At present, it has been applied in many fields such as "multiple regulations in one", urban planning implementation supervision, environmental protection and governance, natural resource management, agriculture, tourism, public pension, etc.. It provides a unified geospatial public information database for the reform of the ecological civilization system, the safety of people's livelihood, emergency disaster relief, major national conditions and the investigation of state power.

\subsection{Background and Research}

The fundamental geographic national condition monitoring scope is the land territory in China, and the monitoring period is once a year. The monitoring work has the characteristics of large task volume, short period, many types of results, and many operating units. For this purpose, how to carry out quality control during the production of results is studied It is of great significance to work continuously to ensure the provision of stable and reliable fundamental geographic national condition monitoring information products.

This article monitors the actual situation of production and organization methods, technical methods, and results requirements for geographical and national conditions. Innovative development in many technical fields such as quality control methods, quality control content, achievement quality acceptance evaluation, software research and development, etc., has established a fundamental geographic national condition monitoring quality control system. It has been applied in the quality control of fundamental geographic national condition monitoring carried out in the past four years from 2016 to 2019 , and the annual results have met the quality control goals of the technical design requirements of the project.

\section{ACHIEVEMENT PRODUCTION TECHNOLOGY PROCESSTITLE}

The basic monitoring images and results data of the previous year are used as monitoring background data, by using newly acquired high-resolution aerospace remote sensing images, using human-computer interaction to identify and obtain the change information in remote sensing images, carry out update and collection of fundamental geographic national condition monitoring data such as surface coverage classification, geographic national condition element data, and metadata. At the same time combined with field investigation and verification, Overlay the use of the latest basic geographic information data and collect and integrate civil affairs, land, environmental protection, construction, transportation, water conservancy, 
agriculture, statistics, forestry thematic data and other technologies and methods to develop production.

After the production process and final results have passed a series of quality control activities, Formation of annual surface coverage classification, Geographical factors, Remote sensing interpretation sample, field investigation and verification, production metadata, databases and statistical analysis fundamental geographic national condition monitoring results. Figure 1.

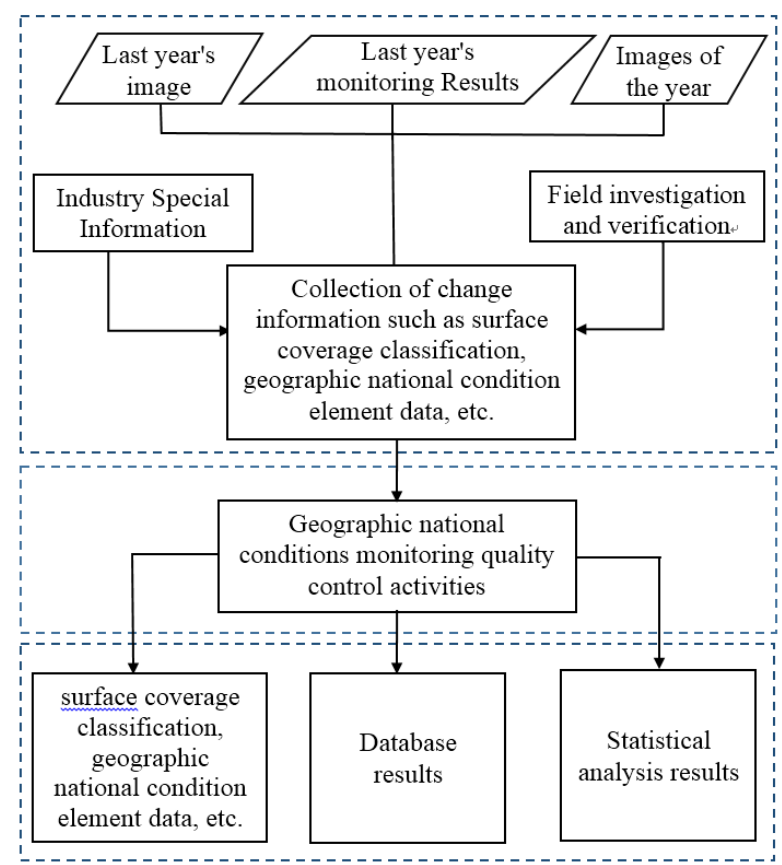

Figure 1.Production technology process

\section{CONSTRUCTION OF QUALITY CONTROL SYSTEM}

The construction of the quality control system focuses on innovation and development in many technical fields such as quality control content and methods, process quality control, achievement quality control, and quality inspection software R \& D, which effectively guarantees the quality of the achievements.

\subsection{Quality control content and methods}

Established the quality control methods of hierarchical management and step-by-step control, adopted the three-level quality control mode of national, provincial, and production units, clarified the quality management responsibilities at all levels. Process quality control by adopting the method of general inspection and sampling inspection, and achievement quality control by adopting the method of general survey and detailed investigation, realized the whole process control of the fundamental geographic national condition monitoring production, Effectively ensure that the quality of the fundamental geographic national condition monitoring results meet the comprehensive, true and accurate design requirements.

\begin{tabular}{|c|c|c|}
\hline $\begin{array}{c}\text { Quality } \\
\text { control } \\
\text { activities }\end{array}$ & $\begin{array}{c}\text { Quality } \\
\text { control sub- } \\
\text { activities }\end{array}$ & Main content \\
\hline \multirow{2}{*}{$\begin{array}{c}\text { Process } \\
\text { quality } \\
\text { control }\end{array}$} & $\begin{array}{c}\text { Process } \\
\text { quality } \\
\text { inspection }\end{array}$ & $\begin{array}{l}\text { The provincial task undertaking } \\
\text { unit organizes full-time quality } \\
\text { inspection personnel to carry out } \\
\text { the whole process quality } \\
\text { inspection activities of each } \\
\text { operation department undertaking } \\
\text { the monitoring task of the unit }\end{array}$ \\
\hline & $\begin{array}{c}\text { Process } \\
\text { quality } \\
\text { supervision } \\
\text { spot check }\end{array}$ & $\begin{array}{l}\text { National quality inspection agencies } \\
\text { conducted spot checks on the } \\
\text { implementation and effectiveness of } \\
\text { process quality inspections for } \\
\text { provincial tasks undertaken } \\
\text { nationwide }\end{array}$ \\
\hline \multirow{3}{*}{$\begin{array}{l}\text { Results } \\
\text { quality } \\
\text { control }\end{array}$} & $\begin{array}{l}\text { Two-level } \\
\text { inspection }\end{array}$ & $\begin{array}{l}\text { Process quality inspection of } \\
\text { surveying and mapping unit } \\
\text { operation department and final } \\
\text { inspection of surveying and } \\
\text { mapping unit quality management } \\
\text { department }\end{array}$ \\
\hline & $\begin{array}{c}\text { results } \\
\text { quality } \\
\text { Acceptance }\end{array}$ & $\begin{array}{l}\text { results quality Acceptance } \\
\text { Provincial quality inspection } \\
\text { agencies perform quality inspection } \\
\text { and acceptance of the monitoring } \\
\text { tasks undertaken by their units }\end{array}$ \\
\hline & $\begin{array}{l}\text { Results } \\
\text { quality } \\
\text { review }\end{array}$ & $\begin{array}{l}\text { National quality inspection agencies } \\
\text { conduct quality inspections of key } \\
\text { quality elements of key } \\
\text { achievements after acceptance by } \\
\text { provincial quality inspection } \\
\text { agencies nationwide }\end{array}$ \\
\hline
\end{tabular}

Table 1. Main content

\subsection{Process quality control}

Formulated the "Regulations on Process Quality Inspection and Process Quality Supervision Spot Check of Fundamental Geographic National Condition Monitoring Process" which include the main content of process quality control, inspection methods and evaluation methods, carried out process quality control activities on the quality management of monitoring production and the key links of production in the main stage, found problems affecting the quality of monitoring results in time, corrected technical deviations in the production process that affected the quality of results, and effectively guaranteed the quality of the production process Meet the goals of technical design requirements.

\subsubsection{Main content and inspection method}

Process quality control includes two quality control subactivities: process quality inspection and Process quality supervision spot check. The main contents include quality management and production process inspection.

The quality management situation inspection adopts the overall inspection method, which is carried out through the methods of consulting records, inquiring and communicating, and on-site inspection. The process quality inspection quality management situation research has formulated the establishment and operation of the organization implementation organization, the effectiveness of the preparation of professional technical design documents, 7 items, including production process compliance, internal training implementation and effectiveness, equipment configuration identification, technical problem handling, two- 
level inspection compliance and normativeness, 22 quality status inspection items; process quality supervision The spot check quality management situation research and development includes the project organization implementation situation, implementation plan preparation situation, provincial training organization and development effect situation, design verification development situation, special data collection and utilization situation, technical problem mechanism establishment and operation situation, process quality inspection development 7 items such as effect and 25 items for quality check.

The quality inspection of the results production process adopts the method of sampling inspection. Through the methods of querying data, reference data comparison, field verification and other methods, the key production processes such as surface coverage classification and geographical national conditions elements are inspected. The research has formulated 6 key quality control procedures including 51 image quality inspections, including image processing, change information collection, field investigation and verification, remote-sensing image troubleshooting samples, internal industry editing and sorting, and pre-test results.

\subsubsection{Process quality evaluation}

In order to grasp the process quality control situation, a fundamental geographic national condition monitoring process quality evaluation method was developed to evaluate the carried out process quality quality control sub-activities. The inspection item is the smallest unit of evaluation. According to the percentage of compliance with the regulations, it is divided into: compliance, basic compliance, and non-compliance.

The process quality control sub-activities are determined according to the proportion of "conformance" of the inspection results of the inspection items of the process quality control activities. The inspection items are "conformance" greater than or equal to $90 \%$ of the total inspection items, and the "standard" when there is no "non-compliance"; The inspection items are "basic compliance", and "conformance" is greater than or equal to $90 \%$ of the total inspection items as "basic specifications"; the inspection items are "non-compliance" and greater than $10 \%$ of the process quality supervision spot check items are "nonstandard".

\subsection{Results quality control}

Combining the characteristics of monitoring results and the inspection standards of digital surveying and mapping products, the "Fundamental Geographic National Condition Monitoring Results Quality Inspection and Acceptance" has been formulated including 6 categories of results including surface coverage classification, geographical national conditions elements, production metadata, remote sensing image interpretation samples, databases, and statistical analysis And quality assessment regulations ", established a comprehensive and operable monitoring results inspection procedure, quality assessment methods, quality evaluation models and evaluation indicators, which provide an important technical basis for the objective evaluation of fundamental geographic national condition monitoring results.

In addition, on the basis of completing the acceptance, for the three key monitoring results of surface coverage classification, geographical and national conditions elements, and production metadata, a national-level results quality review method, content and indicators have been established to further ensure the reliability and consistency of the national results .

\subsubsection{Acceptance procedures}

Through sampling inspection, the results of units of the same grade and specifications produced under the same technical design book are first grouped into batches of results, and then the sampling units and samples are determined according to the acceptance regulations, and detailed and extra-sample surveys are carried out. When all the detailed samples and out-ofsample surveys are all qualified, the quality of the results is evaluated; when any item fails, the results of the batch are processed unqualified and returned to the original undertaker for processing.

\subsubsection{Achievement quality assessment method}

After the existing evaluation methods were used to evaluate the results of the unit and found that there were limitations and inapplicability, conformity determination, error rate, number of errors and other quality characterization methods were used, combined with the characteristics of the results of different types of monitoring data, the existing evaluation methods were comprehensively used to formulate A method for evaluating the quality of unit achievements is given.

Among them, surface coverage classification, geographical factors, production metadata check items, quality sub-elements, and quality elements calculate scores with reference to GB / T 18316-2008; remote sensing image interpretation samples, databases, statistical analysis quality elements, quality subelements Refer to GB/T 24356-2009 to calculate the score; Unit achievements refer to GB/T 24356-2009 "Quality Inspection and Acceptance of Surveying and Mapping Achievements", adopt the weighted average method to calculate the score, and achieve the objective and scientific quality of the monitoring results through innovative development assessment.

\subsubsection{Achievement quality model and evaluation index}

According to the project's technical requirements for the production of results, a set of quality models and quality evaluation indicators suitable for the monitoring results of geographical and national conditions were established to scientifically evaluate the classification of surface coverage, geographical and national conditions, production metadata, remote sensing image interpretation samples, databases, Statistical analysis, etc., laid the foundation for a total of 6 types of results.

Among them, the ground coverage classification achievements established a quality model including 7 quality elements including spatial reference system, time accuracy, logical consistency, acquisition accuracy, classification accuracy, attribute accuracy, and characterization quality, 12 quality subelements, and 22 inspection items; Geographical factors established a quality model including spatial reference system, time accuracy, logical consistency, position accuracy, attribute accuracy, completeness, and representation quality 7 quality elements, 14 quality sub-elements, and 29 inspection items; geographic national condition elements The data establishes a quality model including 5 quality elements of spatial reference system, logical consistency, position accuracy, attribute accuracy, and completeness, 10 quality sub-elements, and 14 inspection items; the remote sensing image interpretation sample includes 4 quality Elements, 6 quality sub-elements, 8 inspection items quality model; database established 5 quality elements, 19 inspection items quality model; statistical analysis established 4 quality elements, 12 quality sub-elements 14 inspection items Quality model.

Based on the establishment of the quality model, through experimental verification, the accuracy of the classification error of the first class and the second and third classes of the 
quality elements of the surface coverage classification unit was determined, and the importance of the accuracy of the attribute of the production metadata unit was determined. The technical requirements, qualification conditions, and post-qualification scoring methods of quality elements such as the error rate limits of attributes and general attributes have laid the foundation for the quality evaluation of various achievements.

\subsubsection{Results quality review}

Research and formulate the main content and methods of the quality review of the results. For review, the adoption of data verification, reference data comparison and field verification shall focus on the inspection of the provincial acceptance standard and the quality of key monitoring results.

Provincial-level acceptance norms focus on whether independent inspections are carried out by a qualified quality inspection agency, whether all acceptances cover all types of achievements, whether they are conducted on the basis of qualified secondary inspections, and whether key links such as sampling, inspection, quality assessment, and report preparation Meet the requirements of the acceptance regulations, etc.

The inspection of key monitoring results focuses on the inspection of some important quality elements of the three types of monitoring results, such as surface coverage classification, geographical factors, and production metadata. Carry out unit quality evaluation of the results, and the evaluation is based on the evaluation indicators and evaluation methods of the quality element of the results acceptance.

\begin{tabular}{|c|c|c|}
\hline $\begin{array}{l}\text { Review } \\
\text { results }\end{array}$ & $\begin{array}{c}\text { Important quality } \\
\text { element }\end{array}$ & Important items \\
\hline \multirow{4}{*}{$\begin{array}{l}\text { Land cover } \\
\text { classification } \\
\text { data }\end{array}$} & \multirow{2}{*}{$\begin{array}{c}\text { Acquisition } \\
\text { accuracy }\end{array}$} & $\begin{array}{c}\text { Geometric } \\
\text { displacement }\end{array}$ \\
\hline & & Vector edge \\
\hline & \multirow{2}{*}{$\begin{array}{l}\text { Classification } \\
\text { accuracy }\end{array}$} & $\begin{array}{c}\text { Classification } \\
\text { correctness }\end{array}$ \\
\hline & & Completeness \\
\hline \multirow{6}{*}{$\begin{array}{l}\text { Geographical } \\
\text { factors }\end{array}$} & \multirow{2}{*}{ Position accuracy } & $\begin{array}{c}\text { Geometric } \\
\text { displacement }\end{array}$ \\
\hline & & Vector edge \\
\hline & \multirow{2}{*}{ Attribute accuracy } & $\begin{array}{c}\text { Classification code } \\
\text { value }\end{array}$ \\
\hline & & Attribute value \\
\hline & \multirow{2}{*}{ Completeness } & Redundant elements \\
\hline & & Missing elements \\
\hline \multirow{3}{*}{$\begin{array}{l}\text { Production } \\
\text { metadata }\end{array}$} & Attribute accuracy & Attribute correctness \\
\hline & \multirow{2}{*}{ Completeness } & Redundant \\
\hline & & Omission \\
\hline
\end{tabular}

Table 2.Key monitoring results inspection content

The standards for passing the review have been formulated. If the inspection results of the provincial-level acceptance and key monitoring results are passed, the review will pass, otherwise it will not pass.

\subsection{Software development}

In order to solve the situation that the data of the fundamental geographic national condition monitoring results are huge and manual inspection cannot meet the production needs, based on the platform design concept, we have developed a quality inspection software which covers the surface coverage classification, geographical national conditions elements, production metadata.It can perform tasks in batches, help to quickly and accurately find the quality problems in the results. The software inspection is based on the design idea of "inspection rules-inspection items-inspection plan". First, it has formulated two sets of survey and detailed surveys for the results of surface coverage classification and geographical national conditions. The survey plan includes spatial reference system, Concept quality, topological consistency, 3 quality elements, 18 inspection items; detailed investigation plan involves 6 quality elements, 95, including spatial reference system, logical consistency, topological consistency, geographical expression, geometric expression, attribute accuracy, etc. Check items. The second is the inspection plan formulated for the achievements of metadata, including 6 quality elements such as spatial reference system, logical consistency, topological consistency, geometric expression, and attribute accuracy, and 68 inspection items. Thirdly, according to the production characteristics of monitoring results and the quality problems that are prone to occur, a number of inspection items for the characteristics of monitoring production, such as the consistency of unchanging elements and the correctness of the assignment of attribute types of change types, have been developed, which can quickly and accurately identify the existence of monitoring results Quality problems, ensure the accuracy of results, and improve the efficiency of inspection work.

\section{APPLICATION AND ANALYSIS}

\subsection{Process quality control}

In the production process of fundamental geographic national condition monitoring, according to the requirements of the quality control system, the provincial task undertakes to organize the process quality inspection first, and then the state organizes the process quality supervision spot check. At present, state-level process quality supervision spot check is organized twice a year, covering all 31 task-bearing units each time. In the past 4 years, it has achieved 7 full coverage of task-bearing units, and a total of 399 Production unit. It can be seen from the process quality supervision spot check in 2017 and 2018 that the compliance rate of the second batch of inspection items is higher than that of the first batch every year, and the degree of review of each batch of inspection items in 2018 is higher than that of 2017. It can be seen that through the implementation of process quality control work, the universality and tendency problems affecting the quality of monitoring results were found in time, and the relevant units were effectively instructed to correct technical deviations and adjust operation methods in a timely manner, ensuring the quality of the production process in Technical design requirements.

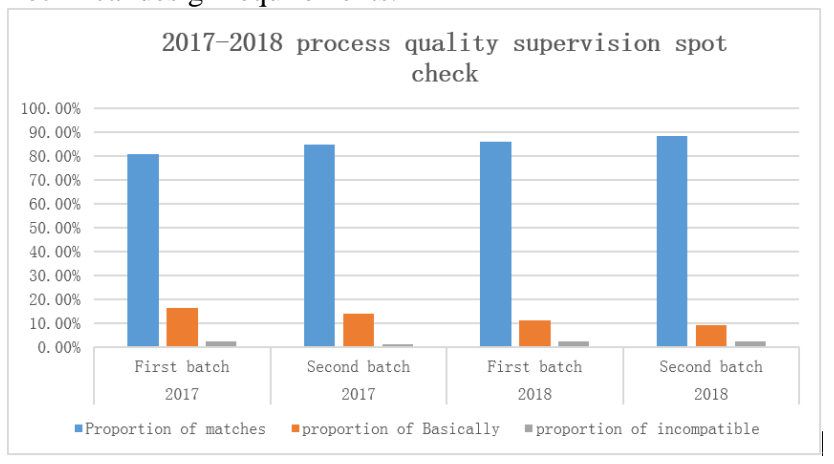

Figure 2. Compliance data of inspection items in 2017 and 2018 


\subsection{Results quality control}

On the basis of completing the production of results and the two-level inspection, the provincial quality inspection agency shall carry out the acceptance of the results in accordance with the acceptance regulations. The acceptance samples cover all the production units and types of achievements of the monitoring tasks, and take into account the typical regional categories and topography. In the past four years, the country has undertaken tasks to check and accept work, and has completed a total of 640 samples of surface coverage classification, Geographical factors, and production metadata scores, which can objectively, comprehensively, truly, and effectively reflect the quality of unit results. The figure below shows the sample scores of a province in 2019.

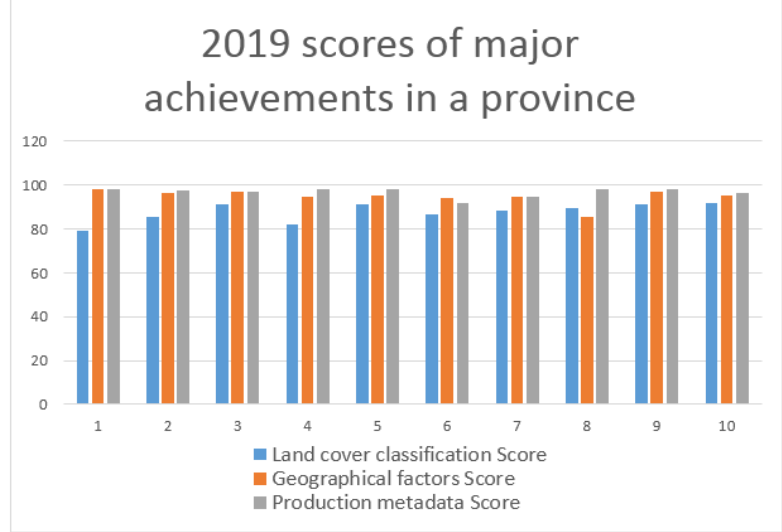

Figure 3. Unit achievement score of a province

After the achievement quality acceptance work is completed, the state organizes a nationwide review of the achievement quality. The quality inspection software is widely used in inspection work in the acceptance of achievement quality and the review of achievement quality. The following picture shows the detailed of the geographical factors using quality inspection software.

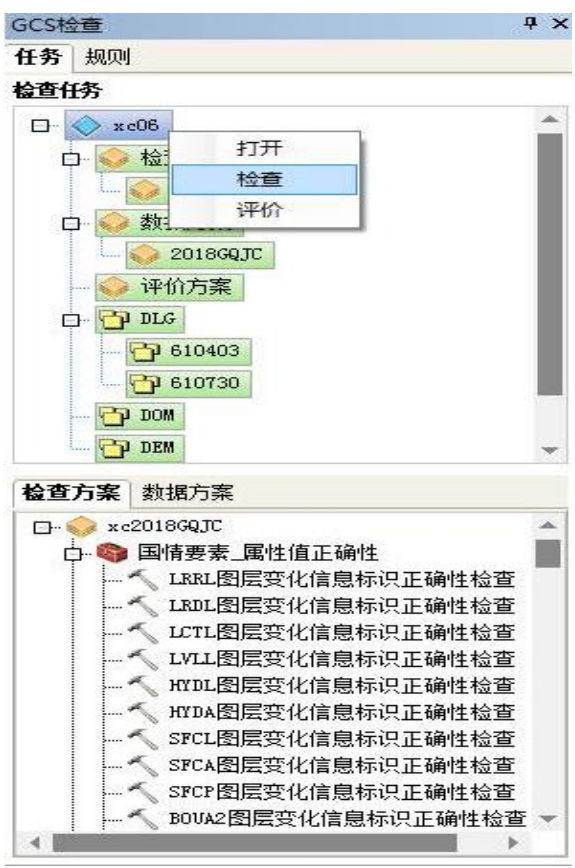

Figure 4.Software application
In the results quality Acceptance and Results quality review, there are still a few quality problems caused by insufficient technical training and inadequate implementation of two-level inspections. Provincial task-bearing units should carry out a comprehensive verification of the results, and the quality inspection should be carried out The agency shall conduct a comprehensive review of the rectification situation and prepare a review report for verification.

\section{CONCLUSION}

This article continuously innovates and develops from the aspects of quality control methods, process quality control, achievement quality evaluation, software development, etc., and builds a basic geographic national condition monitoring quality control system and applies it to quality control work, which can meet the project design requirements and achieve Quality control goals. In the past four years of application, it has been continuously revised and improved, and a complete quality control system has been formed, which provides reference and reference significance for the quality control of other major projects.

\section{REFERENCES}

Zhang, L., Cheng, P.F., Han, W.L., 2015. Investigations of quality evaluation standard for national surveying and mapping key project produces. Bulletin of Surveying and Mapping, 2015(2), 55-57, 63.

Li, W.S., 2013. The geographic conditions monitoring promoting the transformation and upgrading of surveying. Mapping and Geoinformation Industry, 20(5), 11-14.

Chen, J.Y., 2012. Study notes on geographic national condition monitoring. Acta Geodetica et Cartographica Sinica, 41(5), 633-635.

Zhou, X., Ruan, Y.Z., Gui, D.Z. et al., 2013. Study on the system and mechanisms of national geographic condition monitoring. Remote Sensing Information, 28(2), 121-124.

Zhao, Y.S., Zhang J.X. et al., 2019. Research on quality control mehthod of remote sensing image interpretation. Science of Surveying and Mapping, 44(12), 162-167.

Yang, Y., Su, Z.X., Li, D.H., 2019. On the Application of Geographic Conditions Monitoring Results in Natural Resources Ecological Quality Evaluation System, Standardization of Surveying and Mapping, 35(4), 16-19.

Wang, Z.Q. et al., 2019. Application Research of Geographical National Conditions Monitoring in the Evaluation of Urban Construction Land Planning, Journal of Geomatics, 44(4), 2326.

Chen, H.P., Zhang, L., Guo, J., Zhao, Y., Gao, W.C., 2018. Studies on Method of Quality Inspection for Land Cover Achievement. Geomatics \& Apatial Information Technology, 41(7), $72-74$.

Meng, D.X., Zhu, J.H., 2018. Design of an expert system for plant classification based on production rules. Fujian Computer, 2008 (1), 18-19. 